\title{
Breaking Down Barriers to Professional Growth
}

The respiratory care profession has experienced growth in scope, complexity of clinical skills, and diversity of care sites. The need for critical thinking and nontechnical skills has also grown, which has resulted in a demand for respiratory therapists who are not only technically competent but who also demonstrate skills in communication, health literacy, deductive reasoning, management, health policy, and education. ${ }^{1}$ Currently, 3 different pathways for respiratory care entry to practice exist: the associate degree, the baccalaureate degree, and the master's degree. The majority of these programs confer an associate of science (AS) or associate of applied science (AAS) degree. ${ }^{2}$ In 2015, the American Association for Respiratory Care established an aspirational goal for $80 \%$ of practicing respiratory therapists to have earned or be working toward a baccalaureate degree by the year 2020 (http://www.aarc.org/aarc-bodsets-80-bachelor-degree-goal-by-2020. Accessed August $21,2018)$. There is research that indicates that managers prefer to hire respiratory therapists with baccalaureate degrees. ${ }^{3,4}$ Because associate degree programs, both AS and AAS degrees, accounted for $87.2 \%$ of graduates in $2016,{ }^{2}$ it is logical that the primary career pathway to achieve this goal will be through degree advancement programs.

Degree advancement programs allow the respiratory therapist with an AS or an AAS degree to complete his or her education and earn a baccalaureate degree. As of this writing, there are 57 associate-to-baccalaureate degree advancement programs in respiratory care in 31 states (http://www. aarc.org/wp-content/uploads/2018/02/List-of-DegreeAdvancement-Programs-as-of-1.1.18.pdf. Accessed August 21, 2018).

Although degree completion programs are becoming more accessible, not all credits earned during the associate degree education will transfer to a baccalaureate degreegranting institution for the pursuit of a higher degree. Each educational institution establishes its own unique policies

\footnotetext{
Dr Strickland is an employee of the American Association for Respiratory Care.

Dr Strickland has disclosed no conflicts of interest.
}

Correspondence: Shawna L Strickland PhD RRT RRT-NPS RRT-ACCS AE-C FAARC, American Association for Respiratory Care, $9425 \mathrm{~N}$. MacArthur Blvd., Irving, TX 75063.E-mail: Shawna.strickland@ aarc.org.

DOI: $10.4187 /$ respcare. 06593 for accepting, or for not accepting, credits from other educational institutions. ${ }^{5}$ Coursework completed during the AS or AAS degree program may not be of a specific complexity level or have a corresponding course at the institution to which the student is transferring. In some

See the Original Study on Page 1207

cases, the institutions are accredited by different agencies, and none of the credits from the institution that conferred the AS or AAS degree will be accepted by the transfer institution. These situations force the student to enroll in general education coursework in addition to the primary degree completion curriculum, which leads to increased cost and time for degree completion. The graduate, depending on the size of this burden, may be discouraged from pursuing a higher degree.

Educational institutions can engage in articulation or transfer agreement institutions to make the transition process easier for graduates. These agreements guarantee that specific classes from the associate degree-conferring institution will transfer to the accepting institution in a specific way to count toward the baccalaureate degree. However, information about degree advancement and articulation agreements may not be readily available to the graduate seeking to advance his or her degree, which leads to confusion and missed opportunities.

In addition to the issues with accessibility and transfer credits, the graduate may not have enough information about degree advancement options. In this issue of RESPIRATORY CARE, Becker and Vargas ${ }^{6}$ sought to identify the proportion of AS and AAS degrees in respiratory care that encourage a pathway to baccalaureate degrees. When using a sample of AS and AAS program Web sites, the researchers identified how each program Web site addressed transfer credit, degree advancement options, and articulation agreements. They discovered that $44 \%$ of the programs provided information to consumers about baccalaureate degrees in respiratory care and only $17 \%$ referred to degree advancement programs specifically. Twenty-nine percent of studied Web sites contained information about articulation or transfer agreements. In addition, none of the studied Web sites mentioned the American Association for Respiratory Care's aspirational goal for $80 \%$ of practicing respiratory therapists to have earned or be working toward a baccalaureate degree by the year $2020 .{ }^{6}$ This lack of 
readily available and accurate information may negatively affect the personal and professional development path of the graduate as well as the growth of the profession.

As the role of the respiratory therapist expands in scope and complexity, the need for advanced degrees will continue to increase. Affording respiratory therapists the opportunity to expand their knowledge and skills through formal education provides additional avenues for professional growth. Indeed, ensuring that new students, current students, and graduates have access to transparent and accurate degree advancement information and opportunities benefits all stakeholders and reduces barriers for graduates to earn higher degrees, further their careers, and contribute to safe, effective patient care.

Shawna L Strickland PhD RRT RRT-NPS RRT-ACCS AE-C FAARC

American Association for Respiratory Care Irving, Texas

\section{REFERENCES}

1. Barnes TA, Gale DD, Kacmarek RM, Kageler WV. Competencies needed by graduate respiratory therapists in 2015 and beyond. Respir Care 2010;55(5):601-616.

2. Commission on Accreditation for Respiratory Care. 2017 Report on Accreditation in Respiratory Care Education. Bedford, TX: Commission on Accreditation for Respiratory Care; 2018.

3. Becker EA. Respiratory care managers' preferences regarding baccalaureate and master's degree education for respiratory therapists. Respir Care 2003;48(9):840-858.

4. Kacmarek RM, Barnes TA, Durbin CG. Survey of directors of respiratory therapy departments regarding the future education and credentialing of respiratory care students and staff. Respir Care 2012;57(5): 710-720.

5. Simone SA. Transferability of postsecondary credit following student transfer or coenrollment (NCES 2014-163). Washington, DC: National Center for Education Statistics; 2014.

6. Becker EA, Vargas J. Communication of career pathways through associate degree program websites: a baseline assessment. Respir Care 2018;63(10):1207-1213. 